\title{
Application of Stabilized Silver Nanoparticles as Thin Films as Corrosion Inhibitors for Carbon Steel Alloy in $1 \mathrm{M}$ Hydrochloric Acid
}

\author{
Ayman M. Atta, Hamad A. Allohedan, Gamal A. El-Mahdy, and Abdel-Rahman O. Ezzat \\ Chemistry Department, College of Science, King Saud University, P.O. Box 2455, Riyadh 11451, Saudi Arabia \\ Correspondence should be addressed to Ayman M. Atta; aatta@ksu.edu.sa
}

Received 29 August 2013; Revised 22 October 2013; Accepted 23 October 2013

Academic Editor: Tianxi Liu

Copyright (c) 2013 Ayman M. Atta et al. This is an open access article distributed under the Creative Commons Attribution License, which permits unrestricted use, distribution, and reproduction in any medium, provided the original work is properly cited.

Nanometer scaled materials have attracted tremendous interest as corrosion protective films due to their high ability to form selfassembled films on the metal surfaces. It is well known that the silver nanoparticles have higher reactivity towards aqueous acidic solution. The present work aims to prepare coated silver nanoparticles to protect carbon steel alloys from aqueous acidic corrosive media. In this respect, $\mathrm{Ag}$ nanoparticles colloid solutions were produced through reducing $\mathrm{AgNO}_{3}$ separately with trisodium citrate in an aqueous solution or in the presence of stabilizer such as poly(ethylene glycol)thiol and poly(vinyl pyrrolidone). The morphology of the modified silver nanoparticles was investigated by TEM and DLS. UV-Vis absorption spectrum was used to study the effect of $\mathrm{HCl}$ on the stability of the dispersed silver nanoparticles. The corrosion inhibition efficiency of the poly (ethylene glycol)thiol, the self-assembled monolayers of Ag nanoparticles, was determined by polarization method and electrochemical impedance spectroscopy (EIS). Polarization curves indicated that the coated silver poly (ethylene glycol)thiol acted as a mixed type inhibitor. The data of inhibition efficiencies obtained measured by polarization measurements are in good agreement with those obtained with electrochemical impedance.

\section{Introduction}

Due to its particular properties (excellent thermal and electrical conductivity, malleability, ductility, etc.), iron is widely used in industrial production and many other areas which make it very important to research corrosion and protection of iron and its alloy. The high anticorrosion materials for iron are called self-assembled materials (SAMs). The stable SAMs [1] form can prevent corrosive ions from transferring to the metal surface and can protect the metal from corrosion effectively $[2,3]$. There are a lot of materials that have been used to make SAMs as corrosion inhibitors on the copper and iron [4-6]. Shimura and Aramaki [7-9] succeeded to protect iron from corrosion by covering it with ultrathin films. Feng and coworkers investigated self-assembly technique to enhance the iron resistance against environmental corrosion $[10,11]$.

In the past few years, many efforts have been focused on the fabrication of Ag nanoparticles due to their unique chemical and physical properties [12]. At present, there are many techniques available for the synthesis of metal nanoparticles, which includes gas reduction process [13], precursor pyrolysis [14], microwave plasma synthesis, hydrodynamic cavitations and liquid chemical reduction $[15,16]$, and laser ablation [17]. However, the synthesis of well-dispersed and active Ag nanoparticles was difficult, partially because the surfactant molecules were ineffectively adsorbed on the surface of nanoparticles, resulting in the agglomeration and oxidation propensity of nanoparticles. It was previously [18] reported that the dispersion of $\mathrm{Ag}$ nanoparticles can be controlled in the presence of modified organic materials based on polymer and thiol derivatives. On the other hand, organic compounds containing heteroatoms (e.g., $\mathrm{N}, \mathrm{O}$, and $\mathrm{S}$ atoms) could be used as stabilizer for Ag nanoparticles [19,20]. In this respect, this work aims to prepare the highly dispersed and stabilized Ag nanoparticles in both aqueous and acidic media. The corrosion inhibition efficiency of iron was measured in the presence of silver nanoparticles modified with poly (ethylene thiol) aqueous acidic solutions using polarization 
method and electrochemical impedance spectroscopy (EIS) techniques.

\section{Experimental}

2.1. Materials. All reagents used in this experiment were analytical grade chemicals. Silver nitrate, trisodium citrate, and poly(vinyl pyrrolidone), PVP molecular weight of $40000 \mathrm{~g} \mathrm{~mol}^{-1}$, are delivered from Aldrich Chemicals Co. and used to prepare citrate stabilized silver nanoparticles. $P$ Toluenesulfonyl chloride, poly(ethylene glycol) monomethyl ether having molecular weight of $550 \mathrm{~g} / \mathrm{mol}$ (MPEG-550), triethylamine, and thiourea (purchased from Aldrich Chemicals Co.) were used without purification.

2.2. Synthesis of Poly(oxyethylene)thiol Monomethyl Ether. PToluenesulfonyl chloride $(0.05 \mathrm{~mol}, 9.82 \mathrm{~g})$ in $80 \mathrm{~mL}$ of methylene chloride was added dropwise to a mixture of $0.05 \mathrm{~mol}$ $(27.5 \mathrm{~g})$ of poly(ethylene glycol) monomethyl ether having molecular weight of $550 \mathrm{~g} / \mathrm{mol}$ (MPEG-550) and $0.05 \mathrm{~mol}$ $(5.06 \mathrm{~g}, 3.67 \mathrm{~mL})$ of triethylamine over 1 hour at $0^{\circ} \mathrm{C}$. The mixture was then stirred overnight at room temperature. A white triethylamine hydrochloride precipitate was filtered off and washed with $50 \mathrm{~mL}$ of methylene chloride. The methylene chloride was removed under reduced pressure to leave pale yellow oil, which was purified by flash chromatography on silica using dichloromethane and acetonitrile $(3: 1, \mathrm{v} / \mathrm{v})$. Solvents were evaporated to give poly(oxyethylene) tosylate monomethyl ether: (65\% yield), colorless oil in both cases.

Poly(oxyethylene) tosylate monomethyl ether $(0.036 \mathrm{~mol})$ and thiourea $(3.1 \mathrm{~g})$ were mixed with $100 \mathrm{~mL}$ ofethanol and refluxed for $24 \mathrm{hrs}$. The mixture was cooled and mixed with solution of $(4.1 \mathrm{~g}) \mathrm{NaOH}$, water $(5 \mathrm{~mL})$, and ethanol $(50 \mathrm{~mL})$. The mixture was refluxed for $3 \mathrm{hrs}$ under nitrogen atmosphere. The reaction mixture was cooled and neutralized with $0.1 \mathrm{M}$ of $\mathrm{HCl}$. Solvents evaporated and the residue was dissolved in ether and dried over $\mathrm{Na}_{2} \mathrm{SO}_{4}$. The ether evaporated to give pale yellow oil of poly(oxyethylene) thiol monomethyl ether (PEGSH; 86\% yield).

2.3. Synthesis of Silver Nanoparticles. Citrate-stabilized silver nanoparticles were prepared by dissolving $9 \mathrm{mg}$ of silver nitrate in $50 \mathrm{~mL}$ of water and bringing it to boiling. A solution of $1 \%$ trisodium citrate $(1 \mathrm{~mL})$ was added under vigorous stirring. The solution was kept at a boil for $1 \mathrm{~h}$ and then allowed to cool at room temperature. The silver nanoparticles were purified by ultracentrifugation ( $30 \mathrm{~min}$ at $30000 \mathrm{rpm}$ ), followed by redispersion in water. The typical yield of citratestabilized silver nanoparticles was around 65\% (with respect to silver).

Silver coated nanoparticles were synthesized by adding $1 \mathrm{~g}$ of PVP and $0.01 \mathrm{~g}$ of PEGSH with silver nitrate solution. The reaction was completed as reported for citrate stabilized silver nanoparticles.

2.4. Characterization of AgNP. Transmission electron microscopy (TEM) micrographs are recorded using a JEOL JEM2100F. A few drops of silver nanoparticle solution were diluted into $1 \mathrm{~mL}$ of ethanol, and the resulting ethanol solution was placed onto a carbon coated copper grid and allowed to evaporate.

Samples for dynamic light scattering (DLS) were prepared by diluting several drops of the silver nanoparticle solution into $2 \mathrm{~mL}$ of water under vigorous stirring. The DLS measurements were performed on a Brookhaven Instruments system with a $514.5 \mathrm{~nm}$ argon ion laser (model 85 Lexel Laser) as the light source.

Ultraviolet visible (UV-Vis) absorption spectra were obtained with a Techcomp UV2300 spectrophotometer.

2.5. Electrochemical Measurements. EIS impedance measurements were performed using a Solartron 1470E system (potentiostat/galvanostat) with Solartron $1455 \mathrm{~A}$ as frequency response analyzer. Multistate software was used to run the tests and collect and evaluate the experimental data. Impedance tests were performed in $1 \mathrm{M} \mathrm{HCl}$ with and without inhibitor. $\mathrm{Ag} / \mathrm{AgCl}$ electrode was used as the reference and Pt electrode was used as the counter electrode. The working electrode was prepared from carbon steel with dimensions $1 \mathrm{~mm}$ (width) $\times 10 \mathrm{~mm}$ (length). The impedance data were analyzed and fitted with the simulation $\mathrm{Z}$ View 3.3c, equivalent circuit software.

\section{Results and Discussion}

The fundamental application problem of silver NPs is connected with the sufficient stability of their dispersion allowing the prevention of the aggregation process because the generation of spacious aggregates leads to a loss of the silver activity [21]. Therefore various surfactants and polymers are commonly applied to stabilize these metal colloids [22]. In the previous work [23], a simple method was applied to prepare coated silver nanoparticles based on modified 6propylene-4-nonyl-phenol ethoxy maleate, Noigen R-N10, polymerizable surfactant which was used as dispersing agent for silver nanoparticles. The size and the morphology of the nanoparticles have been examined by conventional and highresolution transmission electron microscopy. The prepared silver nanoparticles have size ranging from 25 to $80 \mathrm{~nm}$. The prepared silver nanoparticles have been employed as corrosion inhibitor for carbon steel in $1 \mathrm{M} \mathrm{HCl}$ solution. In the present paper, the work extended to synthesize more stable AgNP based on more stabilized citrate AgNPs. In this respect, poly(ethylene glycol) monomethyl ether was modified to thiol, which can be self-assembled on AgNPs in the presence of PVP as stabilizer. The conversion of MPEG-550 to thiol MPEG-SH was illustrated in Scheme 1.

The chemical structure of the thiol derivatives of PEG was illustrated using ${ }^{1}$ HNMR and FTIR spectra. In this respect, the ${ }^{1}$ HNMR and FTIR spectra of PEG-SH having molecular weight 750 were selected and represented in Figures 1 and 2, respectively. ${ }^{1} \mathrm{H} \mathrm{NMR}\left(\mathrm{CDCl}_{3}\right)$ illustrated different peaks at $\delta 3.76-3.61\left(\mathrm{~m}, 14 \mathrm{H}, \mathrm{OCH}_{2}\right.$ of PEG), 2.73-2.68 (m, $2 \mathrm{H}$, new $\left.-\mathrm{CH}_{2} \mathrm{~S}\right)$, and $1.62(t, 1 \mathrm{H}$, new $\mathrm{SH}$ group). These peaks indicated the formation of PEG-SH as illustrated in Scheme 3. FTIR spectrum (Figure 2) indicated the formation of thiol 


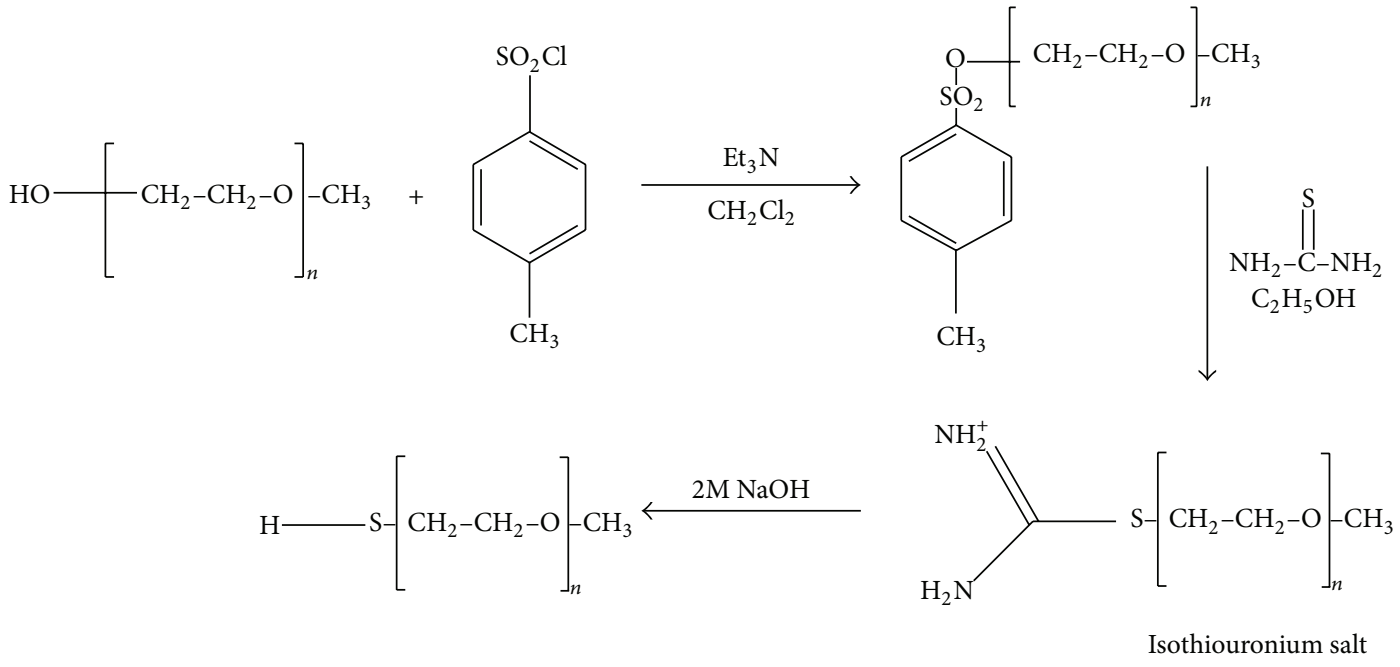

SCHEME 1: Synthesis of MPEG-SH.

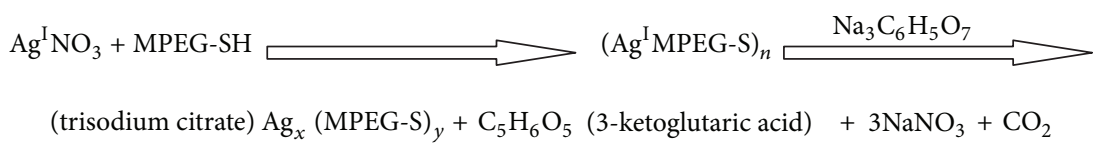

SCHEME 2: Reduction of $\mathrm{AgNO}_{3}$ in the presence of MPEG-SH and sodium citrate solution.

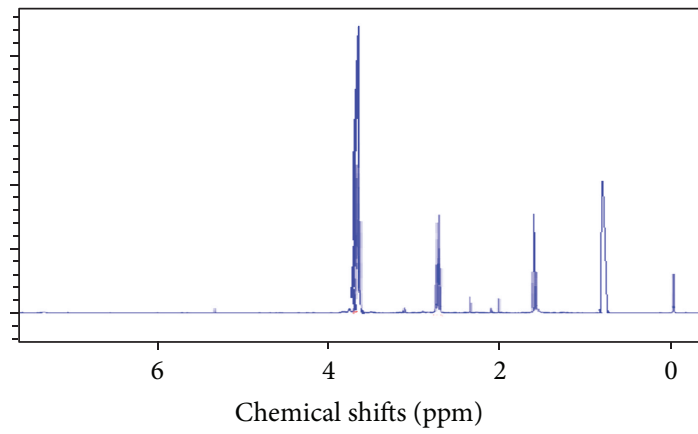

FIGURE 1: ${ }^{1}$ HNMR spectrum of MPEG550-SH.

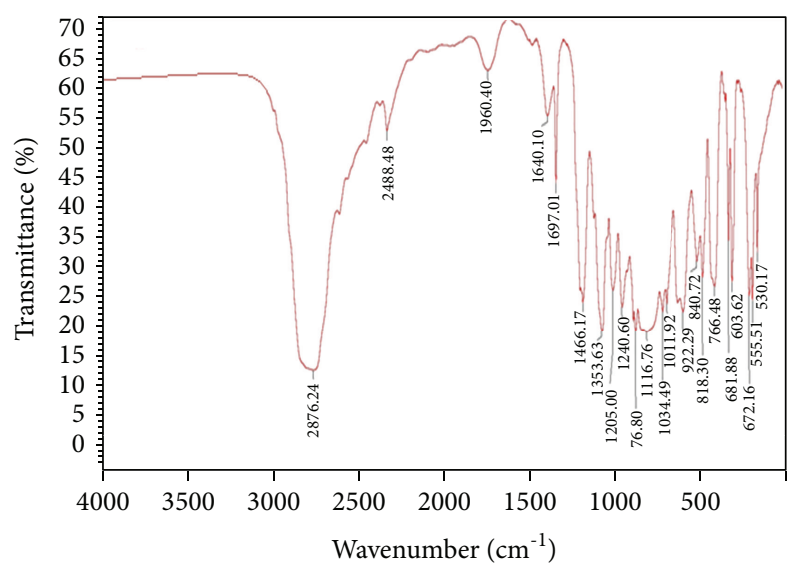

FiguRE 2: FTIR spectrum of MPEG550-SH.

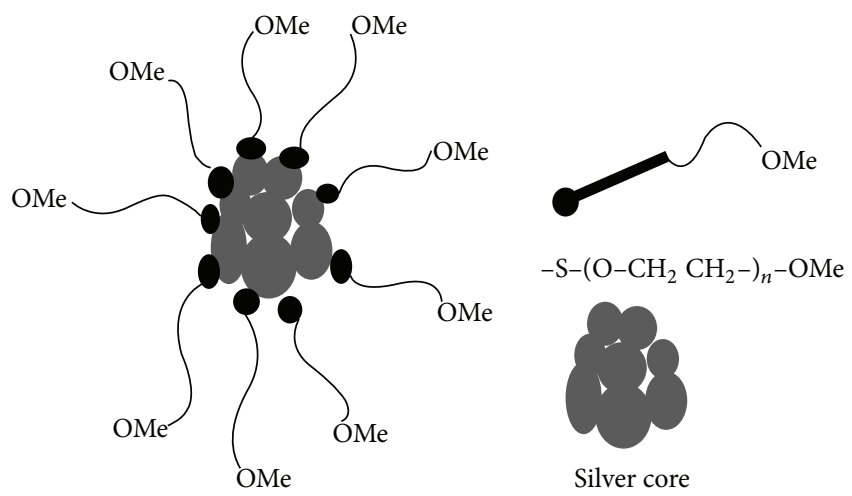

Scheme 3: Self-assembled AgNPS in the presence of MPEG-SH.

derivatives which is confirmed from the appearance of new $\mathrm{SH}$ stretching band at $2550 \mathrm{~cm}^{-1}$. This peak did not appear in spectra of MPEG-550.

3.1. Synthesis of Dispersed Silver Nanoparticles. The mechanism of the synthesis of dispersed silver nanoparticle is based on the reduction of silver nitrate solution in the presence of organic modified thiol derivatives of poly(ethylene glycol) monomethyl ether (PEG-SH) as described in Scheme 2: $\mathrm{Ag}^{I} \mathrm{NO}_{3}$ is reduced to $\mathrm{Ag}^{1+}$ by thiol, yielding a (AgMPEG$\mathrm{SH}) n$ polymer. Aqueous $\mathrm{Na}_{3} \mathrm{C}_{6} \mathrm{H}_{5} \mathrm{O}_{7}$ is added to reduce the silver, and the Agx(MPEG-S) $y$ nanoparticles are formed. The formation of self-assembled silver nanoparticle is illustrated in Scheme 3. 


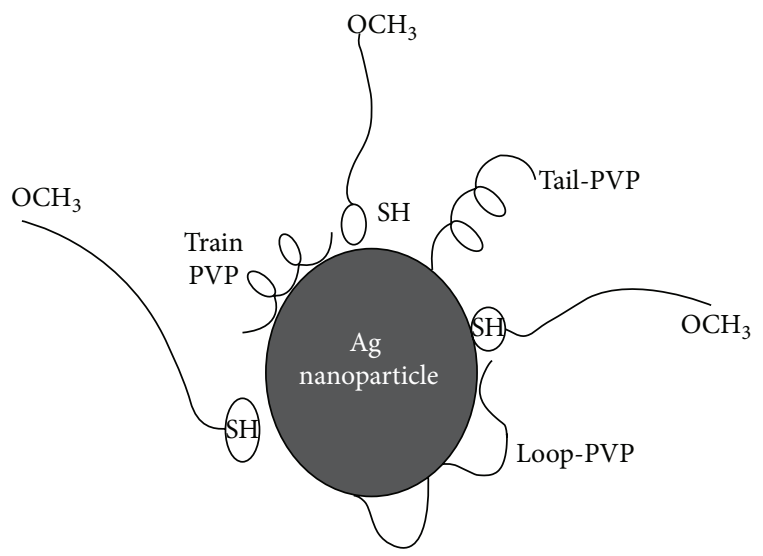

SCHEme 4: Drafts of possible modes of how polymers can be bonded on the silver NP surface.

Considering the adsorption of MPEG-SH and PVP onto AgNPs, Scheme 4 illustrated the formation of self-assembled films on the silver nanoparticles. This model, so-called tail mode, in which the polymer molecule interacts with the solid particle surface only via the end of the polymer chain (Scheme 4), represents a typical interaction mode for the polymer of a high molecular weight having a long linear polymer chain that is not branched. It was a preferable way here using polymer to obtain stable nanoparticles, such as PVP and PEGSH. These polymers have certain polymerization degree and chain length, which can protect the nanoparticles from aggregation during the reduction of silver nitrate [24]. The PVP group are bonded stronger on the silver surface through the nitrogen atom in their molecule, while MPEGs are weakly bonded via the oxygen atom. It was previously reported that $[25,26]$ the lower molecular weight polymers such as polyvinyl alcohol and vinyl acetate copolymer with suitable ionic surfactants can synergistically enhance the stability of oil/water emulsion, while longer chain polymers induce bridging flocculation. The polymer is preadsorbed at the colloidal interface, and polymer-surfactant interaction leads to dramatic changes in repulsive forces due to conformational changes of polymers at the interface, enhancing the stability of the colloid considerably [26]. In the present work, the studied polymers from the MPEG group accomplish a marginal influence on the aggregation stability of the aqueous silver NP dispersion, possibly excluding MPEG 550. The MPEG 550 thiol shows slightly higher stabilizing effect among the tested MPEG polymers which refereed to the lower molecular weight and therefore can be generated a more compact surface layer on the silver NP surface. In this respect, the optimum concentration of MPEG 550 thiol was $(1 \% \mathrm{w} / \mathrm{w})$. The three kinds of silver nanoparticles (Ag NPs) used in this study were citrate AgNP, MPEGSH coated AgNP, and PVP-PEGSH.

A set of UV-Vis absorption spectra of the dispersed nanoparticles in water is presented in Figure 3. As can be seen from this figure, these nanoparticles are relatively monodispersed in size. The preservation of the nanodimensional character of the system modified by PEGSH, with limited

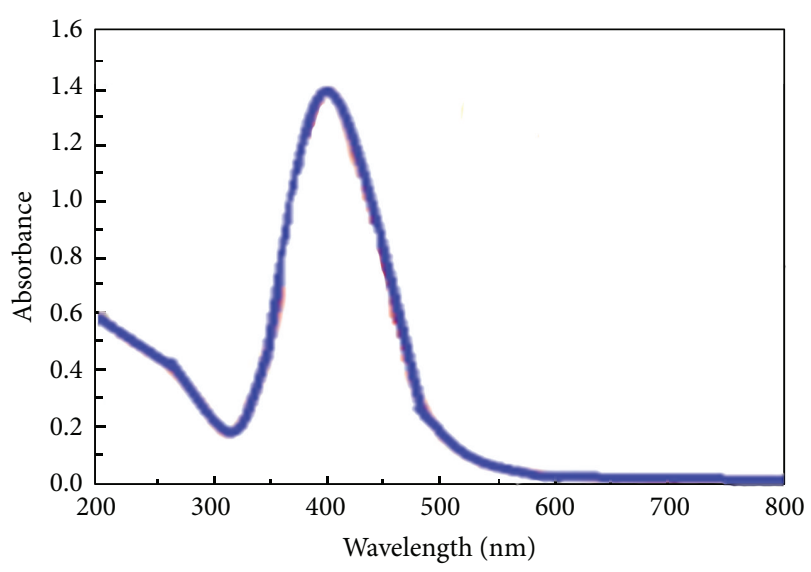

(a)

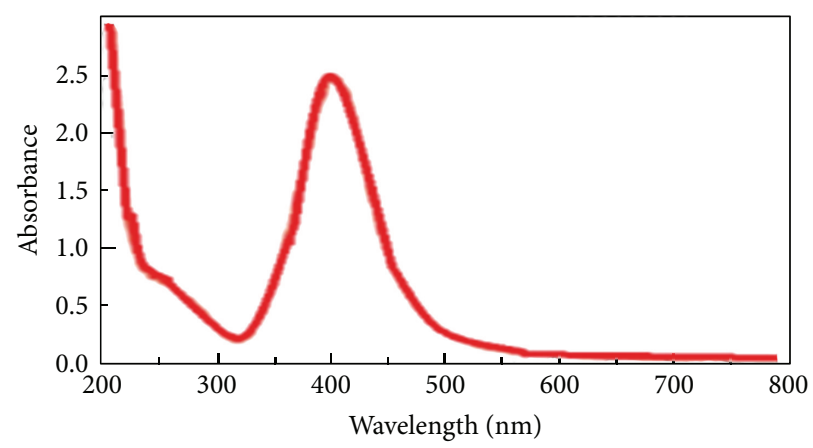

(b)

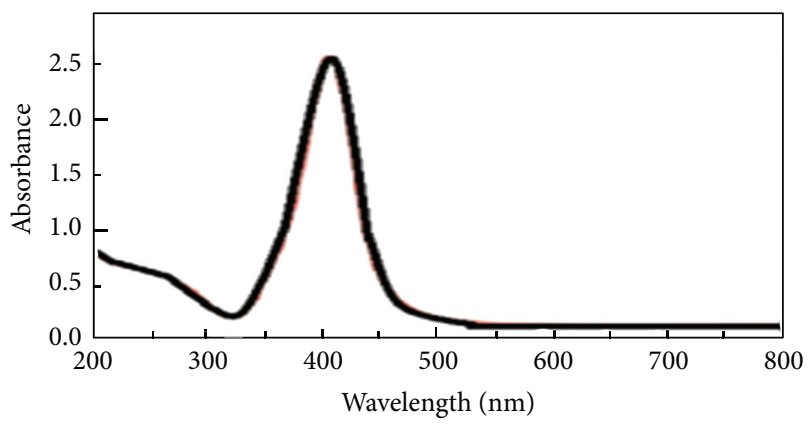

(c)

FIgURE 3: Set of UV-Vis absorption spectrum images for silver nanoparticles: (a) image of the citrate AgNP, (b) PVP/PEGSH AgNPs, and (c) PEGSH AgNPs.

interparticle interactions, is also evident from the UV/Vis absorption spectra (Figure 3) exhibiting relatively intense surface plasmon peak at $405 \mathrm{~nm}$.

The particle size of the prepared AgNPs was illustrated by TEM. In this respect, TEM photos were represented in Figure 4. The average particle size of the AgNPs changed from $12 \mathrm{~nm}$ to $25 \mathrm{~nm}$ and $65 \mathrm{~nm}$ by coating AgNPs with PEGSH and PVP/PEGSH, respectively.

The particle size distribution of $\mathrm{Ag} / \mathrm{PEGSH}-550$ in the presence of $1 \mathrm{M} \mathrm{HCl}$ was estimated using dynamic light scattering (DLS) to evaluate the variation in particle size distribution up to 1 week. Figure 5 represented that the particle size of the AgNP coated with PEGSH-550 ranged between 


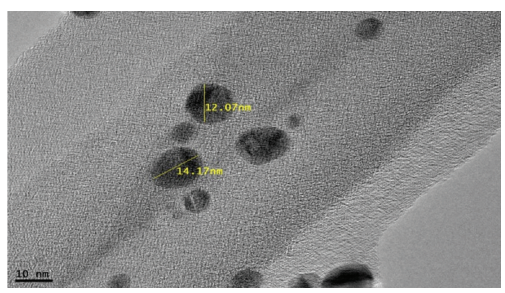

(a)

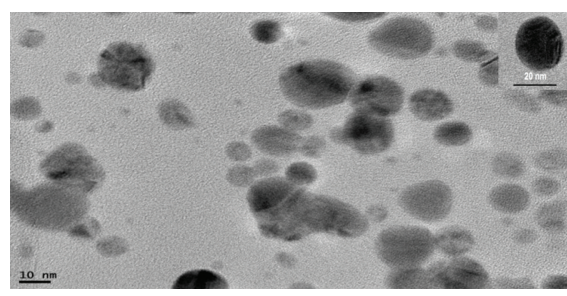

(b)

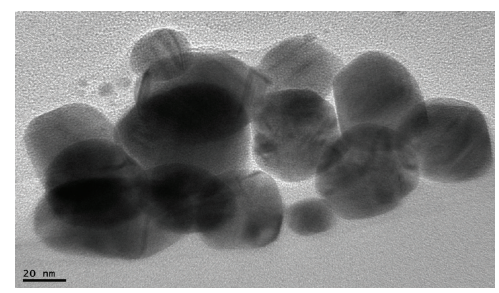

(c)

FIGURE 4: TEM images for silver nanoparticles: (a) citrate AgNP, (b) PEGSH AgNPs, and (c) PVP/PEGSH AgNPs.

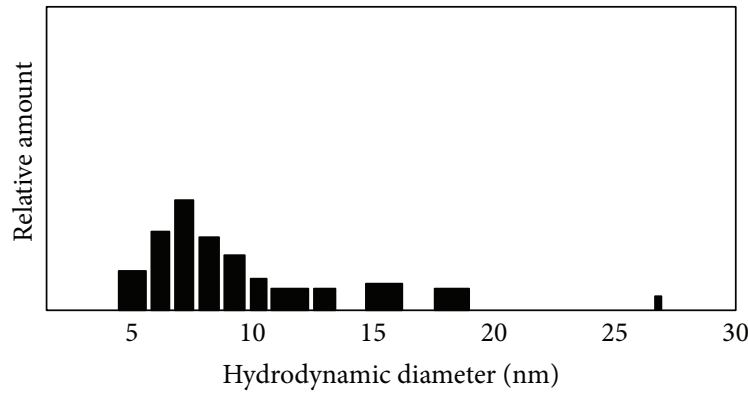

(a)

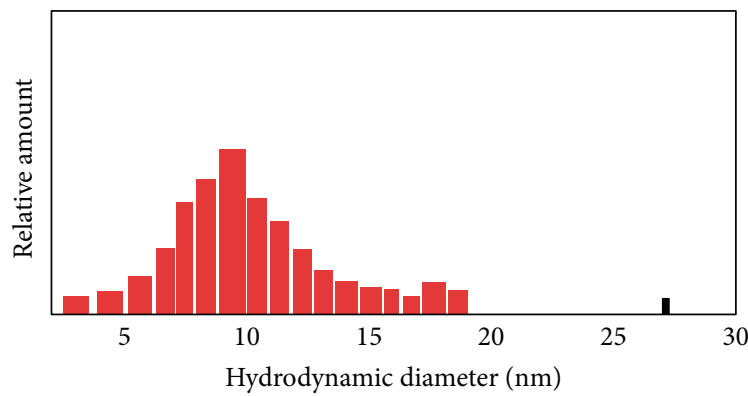

(b)

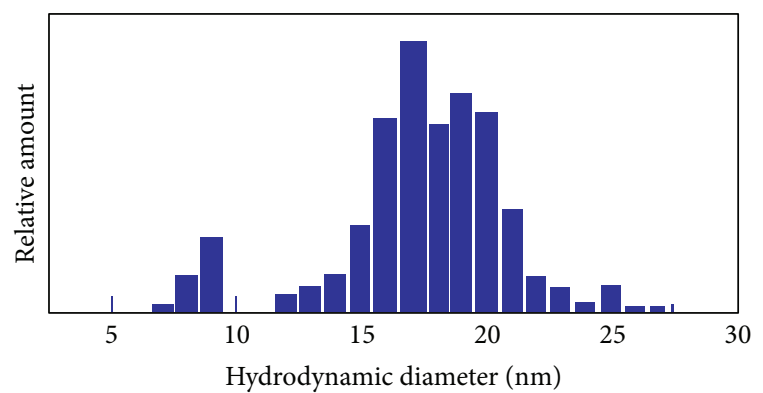

(c)

Figure 5: Particle size distribution of Ag/MPEG-550 in $1 \mathrm{M} \mathrm{HCl}$ at interval times (a) $1 \mathrm{hr}$, (b) $24 \mathrm{hr}$, and (c) 7 days.

5 and $20 \mathrm{~nm}$. The particle size was changed to be uniform between 8 and $12 \mathrm{~nm}$ after $24 \mathrm{hrs}$ of exposure to $1 \mathrm{MHCl}$ (Figure 5(b)). The particle size distribution increased after exposure to $1 \mathrm{M} \mathrm{HCl}$ at 7 days (Figure 5(c)). The particle size diameter increased to be $15-30 \mathrm{~nm}$. The higher stability of silver nanoparticles in $1 \mathrm{M} \mathrm{HCl}$ recommended application as corrosion inhibitors in acidic aqueous solution.

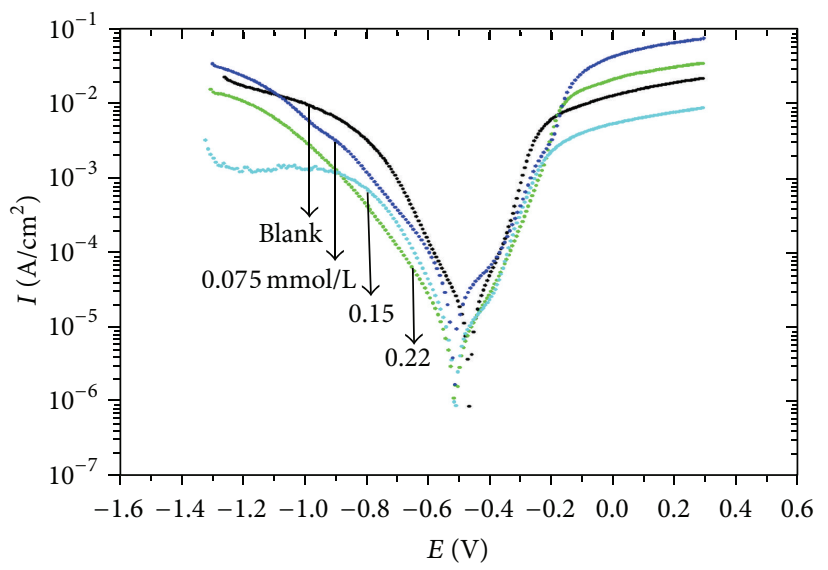

FIGURE 6: Polarization curves for carbon steel in $1 \mathrm{M} \mathrm{HCl}$ solution containing different inhibitor concentrations.

3.2. Polarization Measurements. The influence of various concentrations $(0.075-0.22 \mathrm{mmol} / \mathrm{L})$ of AgNP, MPEGSH coated AgNP, and PVP-PEGSH on the polarization behavior of carbon steel (CS) in $1 \mathrm{M} \mathrm{HCl}$ solution was shown in Figure 6. The presence of Ag-PVP-PEGSH shifts the anodic curves to more positive potentials and the cathodic curves to more negative potentials and lowers the values of current densities. The data reveals that both anodic and cathodic reactions are drastically inhibited. The results can be attributed to the adsorption of Ag-PVP-PEGSH on both anodic and cathodic reactive sites, which inhibited the anodic and cathodic reactions of carbon steel corrosion. The inhibition efficiencies for different inhibitor concentrations were calculated from the following equation [27-30]:

$$
\operatorname{IE~}(\%)=\frac{1-i_{\text {corr }}}{i_{\text {corr }}^{\circ}}
$$

where $i_{\text {corr }}^{\circ}$ and $i_{\text {corr }}$ are the corrosion current densities for carbon steel electrode in the uninhibited and inhibited solutions, respectively. IE\% was calculated and quoted in Table 1. It can be seen from the data presented in Table 1 that inhibition efficiency increases with increasing inhibitor concentration. The results may be attributed to more adsorption of inhibitor molecules on carbon steel surface providing wider surface coverage. It is clear from the obtained corrosion data that the Tafel lines shifted towards more negative and more positive potentials during the anodic and cathodic processes, 
TABLE 1: Inhibition efficiency values for carbon steel in $1 \mathrm{M} \mathrm{HCl}$ with different concentrations of cationic calculated by polarization method and EIS method.

\begin{tabular}{lcc}
\hline $\begin{array}{l}\text { Ag-PVA conc. } \\
(\mathrm{mmol} / \mathrm{L})\end{array}$ & $\begin{array}{c}\text { Inhibitor efficiency } \\
\text { (IE\%) calculated by } \\
\text { polarization method }\end{array}$ & $\begin{array}{c}\text { Inhibitor efficiency } \\
\text { (IE\%) calculated by } \\
\text { EIS method }\end{array}$ \\
\hline 0.22 & 67.63 & 72.76 \\
0.15 & 82.03 & 88.42 \\
0.075 & 90.13 & 90.95 \\
\hline
\end{tabular}

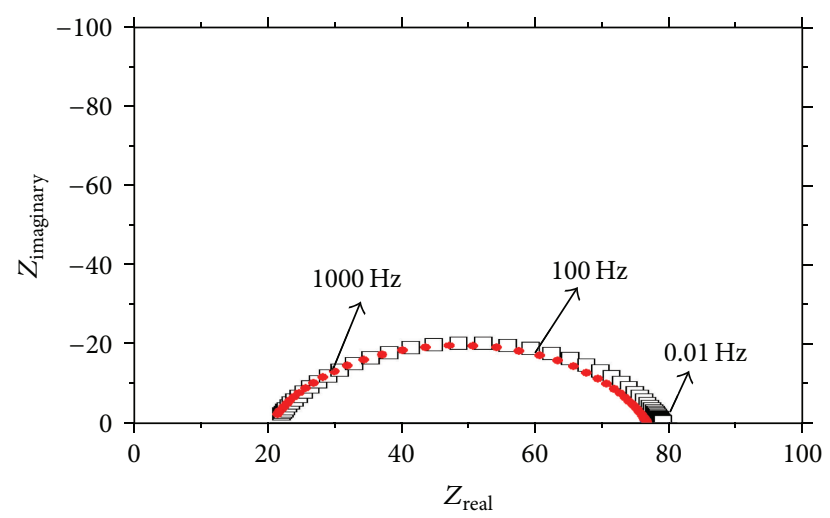

FIGURE 7: Nyquist diagram for carbon steel in $1 \mathrm{M} \mathrm{HCl}$ solution. Open square and closed circle show the experimental and fitted data.

respectively, relative to the blank curve. It can be concluded that Ag-PVP-PEGSH acted as a mixed type inhibitor.

3.3. Electrochemical Impedance Spectroscopy (EIS). Figures 7 and 8 show the Nyquist diagrams of CS in $1 \mathrm{M} \mathrm{HCl}$ without and with different inhibitor concentrations (0.075$0.22 \mathrm{mmol} / \mathrm{L}$ ) of Ag-PVP-PEGSH, respectively. All the impedance spectra exhibit one single semicircle. The diameter of semicircle increases with the increase of AgPVP-PEGSH concentration. It is clear that the corrosion of CS is controlled by the charge transfer and the addition of Ag-PVP-PEGSH to $\mathrm{HCl}$ solution does not change the mechanism of CS dissolution [31, 32] as evident from the semicircular appearance shown in Figures 7 and 8 . The deviation of semicircles from perfect circular shape is often referred to as the frequency dispersion of interfacial impedance [32-34]. This behavior is usually attributed to the inhomogeneity of the metal surface arising from surface roughness or interfacial phenomena $[35,36]$. All experimental spectra were fitted with an appropriate equivalent circuit to find the parameters, which describe and are consistent with the experimental data. Figure 9 shows the Nyquist diagram for carbon steel in $1 \mathrm{M} \mathrm{HCl}$ containing $0.075 \mathrm{mmol} / \mathrm{L}$ of inhibitor showing experimental and fitting data using the inserted plot, which shows the equivalent circuit applied for fitting the impedance data. It consists of solution resistance Rs in series to the constant phase element $\mathrm{CPE}$ and the charge transfer resistance Rct while CPE is

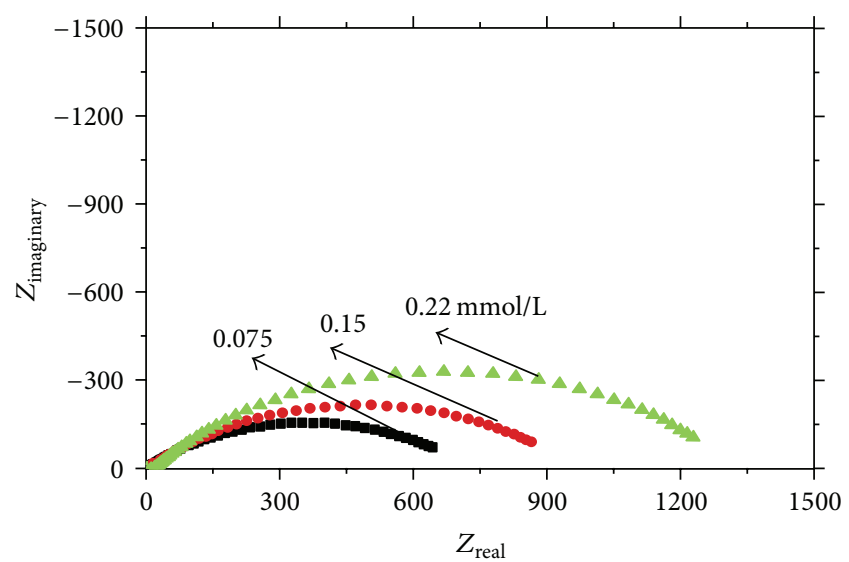

FIGURE 8: Nyquist diagram for carbon steel in $1 \mathrm{M} \mathrm{HCl}$ containing different concentration of inhibitors.

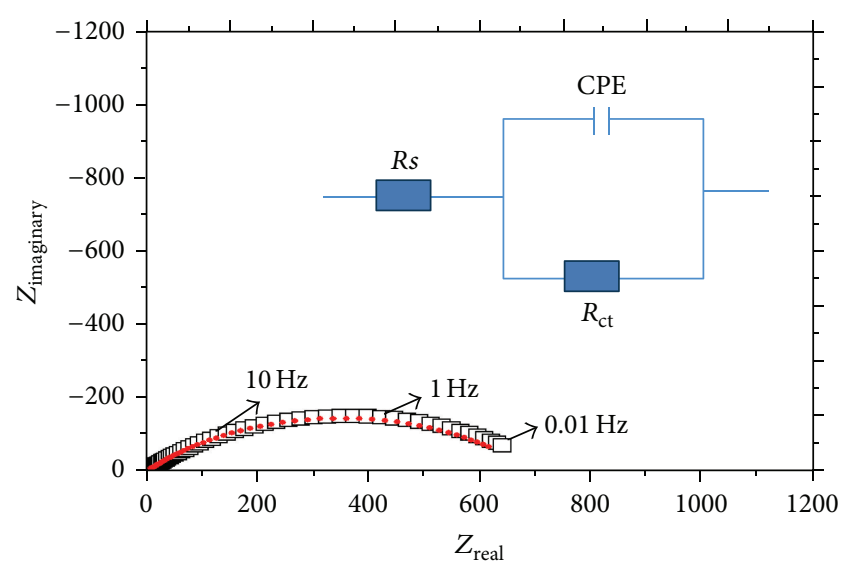

FIgURE 9: Nyquist diagram for carbon steel in $1 \mathrm{M} \mathrm{HCl}$ containing $0.075 \mathrm{mmol} / \mathrm{L}$ of inhibitor showing experimental data (open square) and fitting data (closed circle). The inserted figures show the equivalent circuit used for fitting the impedance data.

parallel to Rct. The impedance of a CPE is described by the expression [37]

$$
Z_{\mathrm{CPE}}=\frac{1}{A \times(j \omega)^{n}},
$$

where $\mathrm{A}$ is the CPE constant, $\omega$ is the angular frequency $(\omega=$ $2 \pi f$, where $f$ is the AC frequency), and $j$ is the imaginary unit and $n$ is CPE exponent which can be used as a gauge of the heterogeneity or roughness of the surface [38]. The inhibition efficiency (IE) is calculated from

$$
\mathrm{IE} \%=\left[1-\left(\frac{R_{\mathrm{ct}}}{R_{\mathrm{ct}}^{*}}\right)\right] \times 100,
$$

where $R_{\mathrm{ct}}^{*}$ and $R_{\mathrm{ct}}$ are the charge transfer resistances with and without inhibitors, respectively. IE\% was calculated and presented in Table 1 . It can be concluded that the $R_{\mathrm{ct}}^{*}$ values increased with inhibitor concentration increment. This may be due to any increase in the surface coverage by the inhibitor, which led to an increase in the inhibition efficiency. The 
inhibition efficiencies calculated from EIS are in good agreement with those obtained from potentiodynamic polarization curves.

\section{Conclusions}

New highly dispersed silver coated nanoparticles were prepared and the results of TEM and DLS indicated that nanoparticles are relatively monodispersed in size. The average particle size of the AgNPs changed from $12 \mathrm{~nm}$ to $25 \mathrm{~nm}$ and $65 \mathrm{~nm}$ by coating AgNPs with PEGSH and PVP/PEGSH, respectively. Polarization data reveal that Ag-poly(ethylene glycol) thiol behaves as a mixed type inhibitor. The inhibition efficiencies obtained by polarization measurements are in good agreement with those obtained with electrochemical impedance spectroscopy for increasing the efficiency of the inhibitor with inhibitor concentration.

\section{Conflict of Interests}

The authors declare that there is no conflict of interests regarding the publication of this paper.

\section{Acknowledgment}

The authors extend their appreciation to the Deanship of Scientific Research at King Saud University for funding this work through Research Group no. RGP-VPP-235.

\section{References}

[1] Y. Xia and G. M. Whitesides, "Soft lithography," Angewandte Chemie-International Edition, vol. 37, no. 5, pp. 550-575, 1998.

[2] H. Mao, C. Li, Y. Zhang, D. E. Bergbreiter, and P. S. Cremer, "Measuring LCSTs by novel temperature gradient methods: evidence for intermolecular interactions in mixed polymer solutions," Journal of the American Chemical Society, vol. 125, no. 10, pp. 2850-2851, 2003.

[3] A. Ulman, "Formation and structure of self-assembled monolayers," Chemical Reviews, vol. 96, no. 4, pp. 1533-1554, 1996.

[4] Y. H. Lai, C. T. Yeh, S. H. Cheng, P. Liao, and W. H. Hung, "Adsorption and thermal decomposition of alkanethiols on $\mathrm{Cu}(110)$," Journal of Physical Chemistry B, vol. 106, no. 21, pp. 5438-5446, 2002.

[5] G. Loepp, S. Vollmer, G. Witte, and C. Wöll, "Adsorption of heptanethiol on $\mathrm{Cu}(110)$," Langmuir, vol. 15, no. 11, pp. 3767-3772, 1999.

[6] K. K. Meagher, A. B. Bocarsly, S. L. Bernasek, and T. A. Ramanarayanan, "Interaction of neopentyl thiol with clean and oxygen-modified Fe(100) surfaces," Journal of Physical Chemistry B, vol. 104, no. 14, pp. 3320-3326, 2000.

[7] T. Shimura and K. Aramaki, "Improvement of the film thickness by modification of the hydroxymethylbenzene SAM with tetraethoxysilane and octanediol for protection of iron from corrosion in $0.5 \mathrm{M} \mathrm{NaCl}$," Corrosion Science, vol. 50, no. 5, pp. 1397-1405, 2008.

[8] T. Shimura and K. Aramaki, "Self-assembled monolayers of $p$-toluene and $p$-hydroxymethylbenzene moieties adsorbed on iron by the formation of covalent bonds between carbon and iron atoms for protection of iron from corrosion," Corrosion Science, vol. 49, no. 3, pp. 1378-1393, 2007.

[9] K. Aramaki and T. Shimura, "Complete protection of a passive film on iron from breakdown in a borate buffer containing $0.1 \mathrm{M}$ of $\mathrm{Cl}^{-}$by coverage with an ultrathin film of two-dimensional polymer," Corrosion Science, vol. 48, no. 1, pp. 209-225, 2006.

[10] Y. Y. Feng, S. H. Chen, W. J. Guo, Y. X. Zhang, and G. Z. Liu, "Inhibition of iron corrosion by 5,10,15,20-tetraphenylporphyrin and 5,10,15,20-tetra-(4-chlorophenyl)porphyrin adlayers in $0.5 \mathrm{M} \mathrm{H}_{2} \mathrm{SO}_{4}$ solutions," Journal of Electroanalytical Chemistry, vol. 602, no. 1, pp. 115-122, 2007.

[11] W. J. Guo, S. H. Chen, Y. Y. Feng, and C. J. Yang, "Investigations of triphenyl phosphate and bis-(2-ethylhexyl) phosphate selfassembled films on iron surface using electrochemical methods, fourier transform infrared spectroscopy, and molecular simulations," Journal of Physical Chemistry C, vol. 111, no. 7, pp. 31093115, 2007.

[12] T. Kizuka, H. Ichinose, and Y. Ishida, "Structure and hardness of nanocrystalline silver," Journal of Materials Science, vol. 32, no. 6, pp. 1501-1507, 1997.

[13] H. Liu, X. Ge, Y. Ni, Q. Ye, and Z. Zhang, "Synthesis and characterization of polyacrylonitrile-silver nanocomposites by $\gamma$ irradiation," Radiation Physics and Chemistry, vol. 61, no. 1, pp. 89-91, 2001.

[14] N. R. Jana, L. Gearheart, and C. J. Murphy, "Wet chemical synthesis of silver nanorods and nanowires of controllable aspect ratio," Chemical Communications, no. 7, pp. 617-618, 2001.

[15] C. S. Strom, X. Y. Liu, and M. Wang, "Solution-induced reconstructive epitaxial nucleation on pseudoflat surfaces of fractal gel-grown ammonium chloride," Journal of Physical Chemistry $B$, vol. 104, no. 41, pp. 9638-9646, 2000.

[16] Z. S. Pillai and P. V. Kamat, "What factors control the size and shape of silver nanoparticles in the citrate ion reduction method?" Journal of Physical Chemistry B, vol. 108, no. 3, pp. 945-951, 2004.

[17] G. Guo, F. Gu, Z. Wang, D. Li, and H. Guo, "Preparation of Zn nanocrystals with different morphologies by laser ablation," Chinese Journal of Nonferrous Metals, vol. 14, no. 10, pp. 1747$1751,2004$.

[18] L. Quaroni and G. Chumanov, "Preparation of polymer-coated functionalized silver nanoparticles," Journal of the American Chemical Society, vol. 121, no. 45, pp. 10642-10643, 1999.

[19] J. L. Elechiguerra, L. Larios-Lopez, C. Liu, D. Garcia-Gutierrez, A. Camacho-Bragado, and M. J. Yacaman, "Corrosion at the nanoscale: the case of silver nanowires and nanoparticles," Chemistry of Materials, vol. 17, no. 24, pp. 6042-6052, 2005.

[20] A. Manna, T. Imae, K. Aoi, M. Okada, and T. Yogo, "Synthesis of dendrimer-passivated noble metal nanoparticles in a polar medium: comparison of size between silver and gold particles," Chemistry of Materials, vol. 13, no. 5, pp. 1674-1681, 2001.

[21] S. Shrivastava, T. Bera, A. Roy, G. Singh, P. Ramachandrarao, and D. Dash, "Characterization of enhanced antibacterial effects of novel silver nanoparticles," Nanotechnology, vol. 18, no. 22, Article ID 225103, 2007.

[22] L. Kvitek, A. Panacek, J. Soukupova et al., "Effect of surfactants and polymers on stability and antibacterial activity of silver nanoparticles (NPs)," Journal of Physical Chemistry C, vol. 112, no. 15 , pp. 5825-5834, 2008.

[23] A. M. Atta, G. A. El-Mahdy, and H. A. Allohedan, "Corrosion inhibition efficiency of modified silver nanoparticles for carbon steel in $1 \mathrm{M} \mathrm{HCl,"} \mathrm{International} \mathrm{Journal} \mathrm{Electrochemical} \mathrm{Science,}$ vol. 8, no. 4, pp. 4873-4885, 2013. 
[24] S. T. Selvan, J. P. Spatz, H. A. Klok, and M. Möller, "Gold-polypyrrole core-shell particles in diblock copolymer micelles," Advanced Materials, vol. 10, no. 2, pp. 132-134, 1998.

[25] J. S. Nambam and J. Philip, "Competitive adsorption of polymer and surfactant at a liquid droplet interface and its effect on flocculation of emulsion," Journal of Colloid and Interface Science, vol. 366, no. 1, pp. 88-95, 2012.

[26] J. Philip, G. Gnanaprakash, T. Jayakumar, P. Kalyanasundaram, and B. Raj, "Three distinct scenarios under polymer, surfactant, and colloidal interaction," Macromolecules, vol. 36, no. 24, pp. 9230-9236, 2003.

[27] F. Bentiss, M. Lagrenée, and M. Traisnel, "2,5-bis(n-pyridyl)1,3,4-oxadiazoles as corrosion inhibitors for mild steel in acidic media," Corrosion, vol. 56, no. 7, pp. 733-742, 2000.

[28] V. Hluchan, B. L. Wheeler, and N. Hackerman, "Amino acids as corrosion inhibitors in hydrochloric acid solutions," Materials and Corrosions, vol. 39, no. 11, pp. 512-517, 1988.

[29] M. A. Amin, S. S. Abd El Rehim, and H. T. M. Abdel-Fatah, "Electrochemical frequency modulation and inductively coupled plasma atomic emission spectroscopy methods for monitoring corrosion rates and inhibition of low alloy steel corrosion in $\mathrm{HCl}$ solutions and a test for validity of the Tafel extrapolation method," Corrosion Science, vol. 51, no. 4, pp. 882-894, 2009.

[30] F. Bentiss, M. Traisnel, N. Chaibi, B. Mernari, H. Vezin, and M. Lagrenée, "2,5-bis(n-methoxyphenyl)-1,3,4-oxadiazoles used as corrosion inhibitors in acidic media: correlation between inhibition efficiency and chemial structure," Corrosion Science, vol. 44, no. 10, pp. 2271-2289, 2002.

[31] X. H. Li, S. D. Deng, and H. Fu, "Inhibition by Jasminum nudiflorum Lindl. leaves extract of the corrosion of cold rolled steel in hydrochloric acid solution," Journal of Applied Electrochemistry, vol. 40, no. 9, pp. 1641-1649, 2010.

[32] L. Larabi, Y. Harek, M. Traisnel, and A. Mansri, "Synergistic influence of poly(4-vinylpyridine) and potassium iodide on inhibition of corrosion of mild steel in $1 \mathrm{M} \mathrm{HCl,"} \mathrm{Journal} \mathrm{of}$ Applied Electrochemistry, vol. 34, no. 8, pp. 833-839, 2004.

[33] L. J. Li, X. P. Zhang, J. L. Lei, J. X. He, S. T. Zhang, and F. S. Pan, "Osmanthus Fragran leaves extract as corrosion inhibitor for carbon steel in hydrochloric acid solution," Asian Journal of Chemistry, vol. 24, no. 4, pp. 1649-1653, 2012.

[34] F. Mansfeld, M. W. Kendig, and S. Tsai, "Recording and analysis of AC impedance data for corrosion studies II. Experimental approach and results," Corrosion, vol. 38, no. 11, pp. 570-580, 1982.

[35] H. Shih and F. Mansfeld, "A fitting procedure for impedance data of systems with very low corrosion rates," Corrosion Science, vol. 29, no. 10, pp. 1235-1240, 1989.

[36] S. Martinez and M. Metikoš-Huković, "A nonlinear kinetic model introduced for the corrosion inhibitive properties of some organic inhibitors," Journal of Applied Electrochemistry, vol. 33, no. 12, pp. 1137-1142, 2003.

[37] R. Macdonald and D. R. Franceschetti, "The electrical analogs of physical and chemical processes," in Impedance Spectroscopy, J. R. Macdonald, Ed., pp. 96-106, John Wiley \& Sons, New York, NY, USA, 1987.

[38] D. A. López, S. N. Simison, and S. R. de Sánchez, "The influence of steel microstructure on $\mathrm{CO}_{2}$ corrosion. EIS studies on the inhibition efficiency of benzimidazole," Electrochimica Acta, vol. 48, no. 7, pp. 845-854, 2003. 

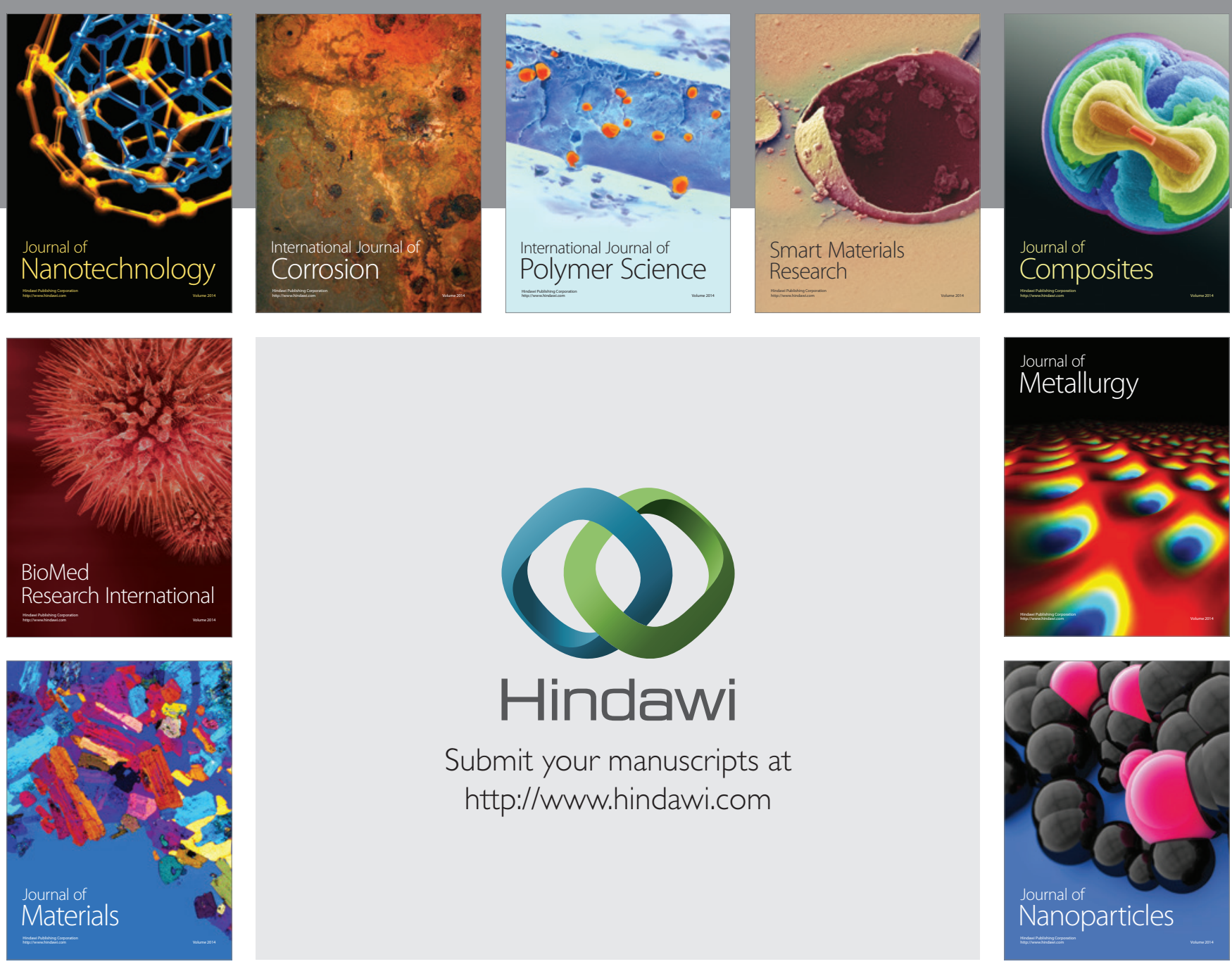

Submit your manuscripts at http://www.hindawi.com
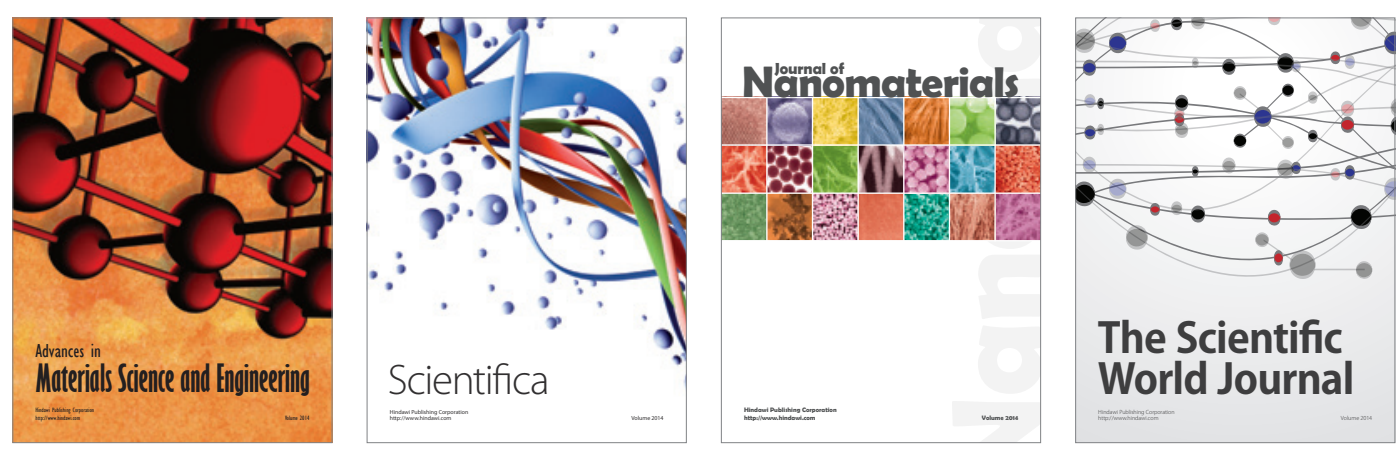

\section{The Scientific World Journal}
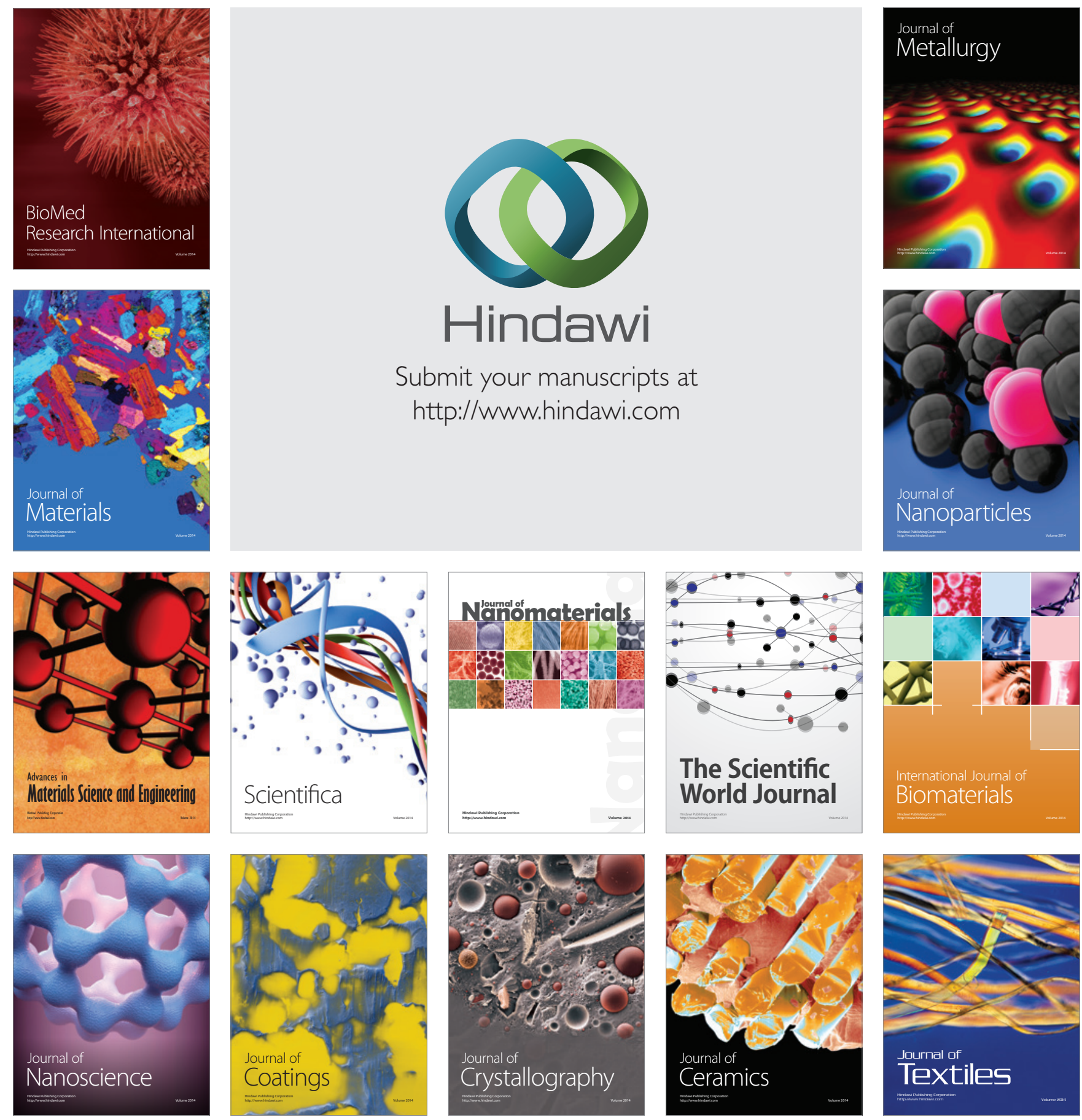